\title{
Влияние доли топ-менеджмента в собственном капитале и других нефундаментальных факторов на инвестиционную активность российских компаний
}

\author{
Удальцов В.E. ${ }^{6}$
}

В данной статье анализируются детерминанты инвестиционной активности российских компаний с акцентом на нефундаментальных факторах, таких как доля топ-менеджмента в собственном капитале компании, тип ее крупных собственников, размер и прозрачность компании. Проведённый анализ показал, что часть выбранных нефундаментальных факторов значимо влияет на инвестииионную активность российских компаний. JEL-классификаџия: G35, G32, G11, J33.

\section{1. Введение}

В фирмах, где необходимо разделение функций владения и контроля компанией, неминуемо возникает конфликт между владельцами и топ менеджерами, осуществляющими контроль и управление компанией.

Владельцы заинтересованы в максимизации стоимости их инвестиций и долгосрочной прибыльности компании, а интересы топменеджера могут заключаться в обеспечении личного дохода безопасности работы, престиже и, как правило, максимизации краткосрочных результатов, с которых менеджеры гарантированно получат бонусы и премии.

Этот конфликт имеет место в одном из важных стратегических решений компании - расходах на НИОКР, инвестициях в долгосрочные инновационные проекты - в общем, в той области, которая отражает инвестиционную активность компании. Очевидно, что большие инвестиции в развитие компании, в частности в долгосрочные проекты, являются стратегией рискованной, но и привлекательной для владельцев компании, которые рассчитывают на положительный результат. Кроме того, владельцы могут диверсифицировать свои вложения путем инвестирования в различные компании, тем самым создавая инвестиционный портфель и сокращая свой финансовый риск. Для менеджеров же, наоборот, инвестиции в такие проекты означают высокий риск (большая доля рискованных инновационных проектов заканчивается крахом) и не приносят им краткосрочного дохода; кроме того, неудачный исход таких проектов может закончиться для менеджера потерей работы

\footnotetext{
${ }^{6}$ Аспирант ГУ-ВШЭ, специализация 08.00.05, кафедра «Экономика и финансы фирмы».
} 
(риск увольнения), - в отличие от финансового риска владельца компании данный риск не может быть диверсифицирован.

Очевидно, что на деятельность компании, и как результат - на её эффективность, оказывает влияние основной владелец компании, которым может выступать как другая компания, институциональный инвестор, так и частное лицо или руководитель компании. Различные типы собственника - достаточно важный фактор, и, как правило, на него всегда делается акцент при рассмотрении эффективности компании и изучении ее взаимосвязи со структурой собственности в компании. Также следует изучить и состав совета директоров компании, в который могут входить как внутренние, так и независимые директора. Они-то и будут оказывать положительное влияние на достижение целей собственников компании.

\section{1. Структура управления компанией: кто мажоритарный собственник?}

Существует множество эмпирических работ, рассматривающих влияние институциональных инвесторов в качестве мажоритарных собственников на финансовую, производственную и инновационную эффективность компании. К примеру, Graves [1988] в своей работе рассматривает влияние институциональных инвесторов на расходы R\&D в расчёте на одного сотрудника по 22 компьютерным компаниям Америки за 1976-1985 года. В данной работе автор выдвинул гипотезу, что институциональные инвесторы имеют «близорукую точку зрения» и тем самым оказывают негативное влияние на вложения в НИОКР в компании, то есть на долгосрочные инвестиции. Данная гипотеза в ходе эмпирического исследования была подтверждена автором. Однако работы других авторов [Baysinger, Kosner и Turk, 1991, и Hansen, Hill, 1991] демонстрируют противоположные результаты, показывая положительное влияние институциональных инвесторов на расходы в НИОКР. Baysinger, Kosner и Turk [1991] получили такие результаты, выполнив аналогичный анализ по данным 176 компаний из Fortune 500. Следует отметить, что в данном исследовании было показано отсутствие систематической зависимости между расходами на НИОКР и влиянием мажоритарных собственников - частных лиц. Это может объясняться разной склонностью к риску среди инвесторов - частных лиц.

В более позднем исследовании на эту тему [Kochhar, Parthiban, 1996] был использован совершенно другой подход: в нем за основу был взят другой показатель «инновационности» компании - количество запущенных новых товаров. Анализ проводился по 135 американским компаниям, исследовались данные за 1989 год. Кроме того, авторы разделили компании на две группы: устойчивые к давлению (пенсионные фонды, взаимные фонды и т.д.) и чувствительные к давлению (страховые 
компании, банки). И в результате исследования показали, что только устойчивые к давлению компании имеют положительный эффект от инноваций. Во всех работах, упомянутых выше, использовались данные по американским компаниям. Напротив, в работе Crashwell [1997] использованы статистические данные 349 австралийских компаний за 1986-1989 годы. В качестве зависимой переменной в данном исследовании авторы использовали прокси-коэффициент Q - Тобина. В результате их работы показали, что зависимость между этим показателем и долей собственности институциональных инвесторов в компании отсутствует, что объясняется «пассивностью» институциональных инвесторов в Австралии до конца 80-х годов.

\section{1. Структура управления компанией: топ-менеджмент - собственник или нет?}

Другая важная область исследования в области корпоративного контроля компанией — анализ влияния доли топ-менеджмента в собственном капитале компании (или наличие у руководящих работников опционов на акции компании) на эффективность компании в финансовом и инновационном плане. Следует отметить, что основное количество работ, описанных ниже, делают акцент на финансовых результатах деятельности компании. Мотивация топ-менеджеров долей в собственном капитале стимулирует их акцентировать усилия не на текущей прибыли компании, от которой они получают в качестве вознаграждения бонусы и премии, а заставляет обеспечивать рост стоимости акции компании. Очевидно, что размер прибыли - не всегда объективный показатель: он может быть низким из-за высоких инвестиций в данный период, а впоследствии обеспечит рост компании. Наличие опционов на акции или самих акций $\mathrm{y}$ топ-менеджеров компании заставляет последних прикладывать усилия для роста стоимости акций компании - то есть показателя, который чувствителен к будущей прибыльности компании. Изучение данной проблематики актуально, и существует ряд эмпирических работ, анализирующих данные не только американских компаний [Hayes, 2000], но и фирм Канады [Zhou, 2000], Японии [Sudipta, 2007].

Существует немало работ [Firth, 1996], [Tevlin, 1996], рассматривающих данную проблему в рамках теоретической модели принципала - агента, задача которой состоит в разработке таких механизмов мотивации топ-менеджмента, при которых цели руководящих работников совпадали бы с целями собственника компании. Было проведено множество эмпирических исследований в 80-х - начале 90-х годов, выявивших взаимосвязь между долей в собственном капитале топ-менеджера и результатами деятельности компании, и использующих в качестве показателя эффективности деятельности благосостояние или 
доход собственника или доход на акцию компании. В более поздних работах [Main, 1996] была использована комбинированная величина, учитывающая заработную плату топ- менеджера и имеющиеся опционы на акции компании у данного менеджера. Авторы данной работы, проверив взаимосвязь указанной величины с результатами деятельности компании (для чего исследовалась текущая динамика акций), показали, что вознаграждение топ- менеджмента чувствительно к результатам деятельности компании. В своей работе Zhou [2000] проанализировал зависимость между вознаграждением топ-менеджеров и результатами деятельности компании, используя данные по 755 канадским компаниям. В результате этого анализа было показано, что размер вознаграждения возрастает с ростом размера компании и корелирует с результатами деятельности компании. Автор показал в своей работе, что в компаниях, предоставляющих коммунальные услуги, уровень вознаграждения ниже, нежели в других отраслях. Кроме того, автор сделал интересные выводы о том, что эластичность вознаграждения топ-менеджмента по объёму продаж выше в больших компаниях, а объявления об увольнении топменеджеров происходят реже в небольших компаниях - в случае если фирма продемонстрировала негативные результаты.

\section{2. Описание модели}

В данной работе, в отличие от описанных выше, акцентируется внимание на влиянии нефундаментальных факторов, таких как доля руководителя в собственном капитале компании, наличие частных лиц среди крупных акционеров, размер компании и т.д., на показатель инвестиционной активности российских компаний, но не на финансовые результаты компании. Проводимые исследования показали, что финансовые факторы, такие как прибыль, рентабельность инвестиций и т.д., не могут в полном объёме объяснить инвестиционное поведение российских компаний, и это свидетельствует о наличии других, нефундаментальных факторов, влияющих на вложения российских компаний в свое развитие, в частности в НИОКР. Поэтому в рамках данной работы проверяется ряд гипотез для выявления нефундаментальных факторов, оказывающих влияние на инвестиционную активность компаний.

Далее будет описан регрессионный анализ, проводимый для описания зависимости показателя инвестиционной активности от нефундаментальных факторов наряду с такими показателями, как прибыль и привлеченный капитал. Использование в регрессии прибыли и привлеченного капитала обусловлено построением наиболее адекватной модели с высокой объясняющей силой регрессанта (инвестиционной активности) рассматриваемых факторов. 


\section{1. Выдвигаемые гипотезы}

\section{Гипотеза 1}

Прибыль предыдущих лет положительно влияет на размер инвестиций компании, так как является источником для инвестиций.

\section{Гипотеза 2}

Привлеченный капитал предыдущих лет положительно влияет на размер инвестиций компании, которые также могут являться источником ее развития и инвестирования проектов.

\section{Гипотеза 3}

Руководители компаний, обладающие долей в собственном капитале компании, должны быть заинтересованы в дополнительных инвестициях для дальнейшего роста стоимости компании, прибылей будущих периодов, так как они будут получать свою долю в этом росте. Другими словами проверяется гипотеза о положительной взаимосвязи между долей руководителей в собственном капитале компании и инвестиционной активностью данной компании.

\section{Гипотеза 4}

Частные лица, являющиеся крупными акционерами компании, заинтересованы в росте инвестиций для развития и роста компании, львиную долю в результатах деятельности которой они имеют. Кроме того, значительная доля в собственном капитале компании позволяет данной группе акционеров оказывать эффективное воздействие на менеджмент, чтобы развивать бизнес согласно своим интересам.

\section{Гипотеза 5}

Высокая доля в собственном капитале, распределенная среди множества мелких акционеров, вероятно, ослабляет контроль над менеджментом компании, который в свою очередь не владеет долей, и это снижает инвестиционную активность компании.

Гипотеза 6

Размер компании и ее прозрачность не должны оказывать существенного влияния на инвестиционную активность, как факторы, не имеющие с ней прямой взаимосвязи.

\section{2. Данные}

Для проверки гипотез были собраны данные по 6154 компаниям добывающей отрасли России и Украины по разделам 10-14 согласно классификатору Nace Rev. 1.1.: 
10. Добыча угля, бурого угля, торфа.

11. Извлечение нефти, природного газа.

12. Добыча урана и тория.

13. Добыча металла.

14. Добыча прочих ископаемых.

Сбор данных осуществлялся без разделения на материнские и дочерние компании, но это не должно повлиять на результаты исследования, так как в работе выделяются компании с мажоритарными собственниками - частными лицами; другие же фирмы - как институциональные инвесторы, так и материнские компании - в качестве мажоритарных собственников не рассматриваются. Кроме того, все компании с нулевыми балансами и неполными данными были удалены из конечной выборки, на основе которой производился анализ.

Данные были собраны с помощью базы «ВанДайк» ${ }^{7}$ по следующим показателям (см. таблицу 1):

Таблица 1

Данные, использованные для регрессионного анализа

1. Название компании

2. Прибыль (убытки) после налогообложения RUB $\quad \mathrm{P}_{2005}$

2005

3. Прибыль (убытки) после налогообложения RUB $\quad \mathrm{P}_{2004}$

2004

4. Прибыль (убытки) после налогообложения RUB $\quad \mathrm{P}_{2003}$ 2003

5. Прибыль (убытки) после налогообложения RUB $\quad \mathrm{P}_{2002}$ 2002

6. Прибыль (убытки) после налогообложения RUB $\quad \mathrm{P}_{2001}$ 2001

7. Индекс прозрачности $\mathrm{I}_{\mathrm{t}}$

8. Доли собственников в собственном капитале $\quad \mathrm{S}_{\mathrm{s}}$ компании

9. ФИО руководителя (топ-менеджера) компании $\quad \mathrm{F}_{\mathrm{CEO}}$

${ }^{7}$ http://www.bvdep.com 
10. ФИО или название акционеров компании $\quad \mathrm{F}_{\mathrm{SH}}$

11. Собственный капитал RUB $2005 \quad \mathrm{E}_{2005}$

12. Собственный капитал RUB $2004 \quad \mathrm{E}_{2004}$

$\mathrm{E}_{2003}$

13. Собственный капитал RUB 2003

14. Собственный капитал RUB $2002 \quad \mathrm{E}_{2002}$

15. Собственный капитал RUB $2001 \quad \mathrm{E}_{2001}$

16. Осязаемые основные средства RUB $2005 \quad$ FA 2005

$\mathrm{FA}_{2004}$

17. Осязаемые основные средства RUB 2004

18. Долгосрочные финансовые инвестиции RUB $\mathrm{LRI}_{2005}$ 2005

19. Долгосрочные финансовые инвестиции RUB $\quad \mathrm{LRI}_{2004}$ 2004

20. Итого активов RUB 2005

$\mathrm{A}_{2005}$

21. Размер компании

$\mathrm{Sz}$

С помощью показателей 8-10 были отсортированы те акционеры, которые одновременно являются руководителями компаний, а также выделены компании с высокой долей в собственном капитале частных лиц и высокой долей, поделенной среди множества мелких акционеров.

\section{3. Регрессионный анализ}

В результате построения ряда регрессий и анализа возможного использования, имеющихся данных были сконструированы следующие показатели в качестве регрессанта и регрессоров:

- в качестве зависимой переменной (Y) для отражения инвестиционной активности был взят показатель, отражающий долю инвестиций в активах компании за 2005 год (ввиду отсутствия данных по долям в собственном капитале руководителей компаний за другие годы расчёт производится только для инвестиционной активности компаний за 2005 год), рассчитанный следующим образом (цифры соответствуют показателям в таблице 1, приведённой выше):

$$
\mathrm{Y}=\left[\left(\mathrm{FA}_{2005}-\mathrm{FA}_{2004}\right)+\left(\mathrm{LRI}_{2005}-\mathrm{LRI}_{2004}\right)\right] / \mathrm{A}_{2005}
$$


В качестве регрессов были взяты следующие показатели:

1. Константа (C).

2. Средняя доля прибыли после налогообложения за 2001-2005 годьи в активах компании $\left(P_{a}\right)$.

$$
\mathrm{P}_{\mathrm{a}}=\left(\mathrm{P}_{2005}+\mathrm{P}_{2004}+\mathrm{P}_{2003}+\mathrm{P}_{2002}+\mathrm{P}_{2001}\right) /\left(5^{*} \mathrm{~A}_{2005}\right) \text {. }
$$

При анализе показателей прибыли по годам в регрессии присутствовала мультиколлинеарность, которую удалось убрать, используя средний показатель доли прибыли в активах, поэтому все показатели приведены в отношении к активам компании.

3. Средняя доля привлеченного (заемного) капитала за 2001-2005 годы в активах компании $\left(C_{a}\right)$.

$$
C_{a}=1-\left(E_{2005}+E_{2004}+E_{2003}+E_{2002}+E_{2001}\right) /\left(5 * A_{2005}\right) .
$$

4. Прозрачность компании $\left(I_{t}\right)$.

Данный показатель был предоставлен в базе «ВанДайк». Его значения изменяются в интервале от 0 до 100. Чем больше индекс, тем более прозрачной считается компания.

\section{5. Доля руководителя в собственном капитале компании $\left(S_{T M}\right)$.}

Данный показатель был рассчитан с использованием показателей долей всех собственников компании $\left(\mathrm{S}_{\mathrm{s}}\right)$, ФИО руководителя компании $\left(\mathrm{F}_{\mathrm{CEO}}\right)$ и ФИО или названия акционеров $\left(\mathrm{S}_{\mathrm{SH}}\right)$. Путем сопоставления двух последних показателей были найдены компании, в которых $\mathrm{y}$ руководителя есть доля в собственном капитале, а далее был определен размер доли данного акционера.

6. Доля в собственном капитале крупных акционеров, которые являются частными лицами $\left(S_{B I}\right)$.

Данный показатель брался как сумма долей частных лиц, о которых дана информация, о ФИО, и доля каждого в отдельности более $0,1 \%$. Расчёт производился с помощью показателей $\mathrm{S}_{\mathrm{s}}$ и $\mathrm{F}_{\mathrm{SH}}$ из таблицы 1.

7. Доля мелких акционеров в собственном капитале $\left(S_{S I}\right)$.

Данный показатель рассчитывался на основании показателей $\mathrm{S}_{\mathrm{s}}$ и $\mathrm{F}_{\mathrm{SH}}$ из таблицы 1 , у компаний, в собственном капитале которых 
определенная доля находится в руках множества акционеров, то есть каждый из них по отдельности владеет маленькой долей (меньше 0,01\%).

\section{8. Размер компании (Sz).}

По данному показателю в базе приводилось 4 варианта размеров компаний: очень большая, большая, средняя, маленькая. Для учёта этого показателя в регрессии были взяты 3 мнимые переменные: D1, D2, D3, значения которых были построены по следующему принципу:

$\mathrm{D} 1=1$, если размер компании $=$ очень большая; иначе $=0$;

$\mathrm{D} 2=1$, если размер компании $=$ большая; иначе $=0$;

$\mathrm{D} 3=1$, если размер компании $=$ средняя; иначе $=0$.

Примечание $к$ сформированной выборке данных: Большое количество данных по компаниям в базе «ВанДайк» содержит пропуски. Так как основная масса компаний, по которым отсутствуют данные, - это либо небольшие компании, либо компании, прекратившие/начавшие свою деятельность в рамках рассматриваемого периода, было принято решение их не рассматривать. В результате регрессия рассчитывалась на основании данных по 1435 компаниям.

\section{4. Результаты регрессионного анализа}

В результате оценки описанной выше регрессии методом МНК были получены следующие результаты.

Таблица 2. Регрессионная статистика

\begin{tabular}{|l|r|}
\hline Регрессионная статистика \\
\hline Множественный R & 0,9255 \\
\hline R-квадрат & 0,8565 \\
\hline Нормированный R-квадрат & 0,8556 \\
\hline Стандартная ошибка & 6,5812 \\
\hline Наблюдения & 1435 \\
\hline
\end{tabular}

Высокое значение нормированного R-квадрата свидетельствует о том, что регрессоры хорошо описывают регрессант.

В рассматриваемой регрессии автокорреляция, мультиколлинеарность отсутствуют, результаты проверки можно посмотреть в Приложении 1 к данной работе.

Вид полученной модели (см. таблицу 3): 
(4) $\mathrm{Y}=0,06+3,10 * \mathrm{P}_{\mathrm{a}}+0,18 * \mathrm{C}_{\mathrm{a}}-0,02 * \mathrm{I}_{\mathrm{t}}+33,65 * \mathrm{~S}_{\mathrm{TM}}+12,60 * \mathrm{~S}_{\mathrm{BI}}+1,67 * \mathrm{~S}_{\mathrm{SI}}+$ $0,04 * \mathrm{D} 1+0,12 * \mathrm{D} 2+0.12 * \mathrm{D} 3$.

Из таблицы 3 легко заметить, что при уровне значимости 5\% на оцениваемый показатель отношения инвестиций к активам (Y) положительно влияет показатель средней доли прибыли в активах $(\mathrm{Pa})$, средняя доля привлекаемого капитала в активах компании $(\mathrm{Ca})$. То есть при росте на $1 \%$ средней доли прибыли в активах $(\mathrm{Pa})$ или средней доли привлекаемого капитала в активах компании $(\mathrm{Ca})$ отношение инвестиций к активам (Y) возрастает на 3,1 \% или 0,18\% - соответственно с поправкой на стандартную ошибку.

Также положительное влияние на отношение инвестиций к активам (Y) оказывают показатели доли руководителя в собственном капитале компании (STM) и доли крупных акционеров - частных лиц (но при уровне значимости 10\%). Рост этих показателей на $1 \%$ приводит к значительному росту доли инвестиций по сравнению с активами (Y), однако здесь следует обратить внимание на большую стандартную ошибку этих коэффициентов. Она возникает из-за того, что в рамках полученной выборки только у 36 компаний долей собственного капитала владеет топ-менеджмент, и у 46 компаний основным собственником является частное лицо.

Остальные коэффициенты в регрессии, отражающие значимость размера компании, прозрачности компании и др., незначимы и не оказывают влияния на оцениваемый показатель (Y). 
Таблица 3. Значение коэффициентов и их значимость

\begin{tabular}{|c|c|c|c|c|c|c|}
\hline $\begin{array}{c}\text { Назва- } \\
\text { ние } \\
\text { пере- } \\
\text { менно } \\
\text { й }\end{array}$ & $\begin{array}{c}\text { Значе- } \\
\text { ние } \\
\text { коэф- } \\
\text { фи- } \\
\text { циента }\end{array}$ & $\begin{array}{c}\text { Стан- } \\
\text { дартная } \\
\text { ошибка }\end{array}$ & $\begin{array}{c}\text { t- } \\
\text { статис- } \\
\text { тика }\end{array}$ & $\begin{array}{c}\text { Р- } \\
\text { значе- } \\
\text { ние }\end{array}$ & $\begin{array}{c}\text { Гипотеза о } \\
\text { неравестве } \\
\text { нулю коэффи- } \\
\text { циента при } \\
\text { уровне } \\
\text { значимости 5\% }\end{array}$ & $\begin{array}{c}\text { Гипотеза о } \\
\text { неравенстве } \\
\text { нулю коэффи- } \\
\text { циента при } \\
\text { уровне } \\
\text { значимости } \\
10 \%\end{array}$ \\
\hline $\mathrm{C}$ & 0,06 & 0,66 & 0,09 & 0,93 & отвергается & отвергается \\
\hline $\mathrm{P}_{\mathrm{a}}$ & 3,10 & 0,05 & 68,87 & 0,00 & не отвергается & не отвергается \\
\hline $\mathrm{C}_{\mathrm{a}}$ & 0,18 & 0,05 & 3,78 & 0,00 & не отвергается & не отвергается \\
\hline $\mathrm{I}_{\mathrm{t}}$ & $-0,02$ & 0,02 & $-0,66$ & 0,51 & отвергается & отвергается \\
\hline $\mathrm{S}_{\mathrm{TM}}$ & 33,65 & 11,44 & 2,94 & 0,00 & не отвергается & не отвергается \\
\hline $\mathrm{S}_{\mathrm{BI}}$ & 12,60 & 5,01 & 2,52 & 0,01 & отвергается & не отвергается \\
\hline $\mathrm{S}_{\mathrm{SI}}$ & 1,67 & 28,33 & 0,06 & 0,95 & отвергается & отвергается \\
\hline D1 & 0,04 & 0,56 & 0,07 & 0,94 & отвергается & отвергается \\
\hline D2 & 0,12 & 0,48 & 0,24 & 0,81 & отвергается & отвергается \\
\hline D3 & 0,12 & 0,50 & 0,25 & 0,80 & отвергается & отвергается \\
\hline
\end{tabular}

\section{3. Выводы}

В результате проведенного регрессионного анализа были получены следующие результаты по выдвинутым гипотезам:

1. Гипотеза 1 и гипотеза 2 о значимости показателя прибыли и привлеченного капитала на инвестиционную активность компании подтвердилась. Тем самым мы показали, что эти два показателя положительно влияют на инвестиционную активность российских компаний. Если показатель прибыли и привлеченного капитала за прошлые годы демонстрирует в среднем рост, то происходит рост инвестиций в компанию, иными словами, компания развивается в инновационном плане - вкладывает в НИОКР, осуществляет долгосрочные финансовые вложения для своего дальнейшего развития. 
2. Гипотеза 3 и гипотеза 4, построенные в отношении нефундаментальных факторов, подтвердились. Согласно результатам анализа получается, что в рассматриваемой отрасли доля собственного капитала в руках менеджмента компании и крупных акционеров частных лиц приводит к повышению инвестиционной активности, что может быть объяснено ориентирами на долгосрочные доходы со стороны менеджмента и акционеров - частных лиц. Второе объяснение может быть найдено в том, что большинство топ-менеджеров, а также крупных собственников - частных лиц, рассматриваемых в данной выборке, обладают большой долей в собственном капитале компании, a следовательно, они заинтересованы в дальнейшем развитии компании и росте её стоимости. Резюмируя вышесказанное, менеджмент компании и собственники - частные лица оказывают положительное влияние на реинвестирование прибыли и прочие решения, связанные с инвестиционной стратегией компании.

3. Гипотеза 5 не подтвердилась. Согласно регрессионному анализу, доля в руках мелких акционеров не оказывает никакого влияния на инвестиционную активность компании, что может объясняться двояким влиянием остальных акционеров данных компаний:

- с одной стороны, крупные акционеры - частные лица могут влиять положительно на инвестиционную активность (см. гипотезу 4);

- с другой стороны, институциональные инвесторы могут оказывать положительное влияние, а следовательно, необходимо дополнительное исследование по размеру общей доли в руках мелких акционеров, так как при определенной доли может получаться положительная зависимость, а при других долях - отрицательная.

Кроме того, согласно полученным результатам, можно заключить, что наличие большого числа мелких акционеров не приводит к снижению инвестиционной активности, так как совет директоров поддерживает интересы данной структуры собственности (множество мелких акционеров) и не даёт менеджменту в данной ситуации неоправданно сокращать расходы на инвестиции.

4. Гипотеза 6 об отсутствии влияния размера и прозрачности компании на её инвестиционную активность, подтвердилась. Как небольшие, так и крупные компании тратят значительные средства на инвестиции, и величина последних не связаны с размером компании, а уж тем более с её прозрачностью.

\section{4. Пути для дальнейшего исследования}

Наличие данных по распределению долей в собственном капитале только за 2005 год снижает возможности данной модели, так как, по сути, 
выводы подвержены макроэкономической ситуации именно этого года, и мы не можем провести анализ по нескольким годам, сравнив результаты. К тому же полученные выводы верны только для добывающей отрасли, что может быть неверно для других отраслей. На мой взгляд, рассмотрение отраслевой специфики может быть интересным продолжением данной работы. Подтверждение гипотезы 3 в данной работе свидетельствует о соответствии интересов собственников и топменеджеров. Однако необходимо провести более глубокий анализ, рассматривающий компании с разным размером доли менеджмента в собственном капитале (по отдельности) на более большой выборке компаний. Для топ-менеджера должна существовать некая предельная доля в собственном капитале, опустившись до которой топ-менеджер будет пересматривать свои цели и интересы в рамках данной компании и ориентироваться на краткосрочные цели, а следовательно, оказывать отрицательное влияние на инвестиционную активность. Поиск данной ставки в отраслевом разрезе является возможным продолжением данной работы.

\section{Приложение 1}

Вид полученной модели:

$\mathrm{Y}=0,06+3,10 * \mathrm{P}_{\mathrm{a}}+0,18 * \mathrm{C}_{\mathrm{a}}-0,02 * \mathrm{I}_{\mathrm{t}}+33,65 * \mathrm{~S}_{\mathrm{TM}}+12,60 * \mathrm{~S}_{\mathrm{BI}}+$ $1,67 * \mathrm{~S}_{\mathrm{SI}}+0,04 * \mathrm{D} 1+0,12 * \mathrm{D} 2+0,12 * \mathrm{D} 3$.

1. Проверка автокорреляции (выполнена с помощью программного обеспечения NCSS2000-PASS2000):

\begin{tabular}{|r|r|r|r|r|r|}
\hline \multicolumn{1}{|l|}{ Лаг } & Корреляция & Лаг & Корреляция & Лаг & Корреляция \\
\hline 1 & $-0,0037$ & 9 & $-0,0052$ & 17 & 0,0032 \\
\hline 2 & 0,0023 & 10 & $-0,0028$ & 18 & $-0,0054$ \\
\hline 3 & 0,0196 & 11 & 0,0007 & 19 & 0,0034 \\
\hline 4 & 0,0267 & 12 & $-0,1042$ & 20 & 0,0042 \\
\hline 5 & 0,0017 & 13 & $-0,0004$ & 21 & 0,0159 \\
\hline 6 & 0,0047 & 14 & 0,0036 & 22 & $-0,0042$ \\
\hline 7 & $-0,0077$ & 15 & $-0,1423$ & 23 & 0,0004 \\
\hline 8 & $-0,0001$ & 16 & 0,0039 & 24 & 0,0620 \\
\hline
\end{tabular}

Автокорреляция значима, если абсолютное значение выше 0,05278

Статистика Durbin-Watson 2,0073

Значение статистики D-W свидетельствует об отсутствии автокорреляции.

2. Проверка мультиколлинеарности (выполнена с помощью программного обеспечения NCSS2000-PASS2000): 


\begin{tabular}{|l|r|r|r|r|}
\hline $\begin{array}{l}\text { Независимая } \\
\text { другенная }\end{array}$ & Вариация & \multicolumn{1}{l}{$\begin{array}{l}\text { R-квадрат } \\
\text { против }\end{array}$} & \multicolumn{1}{l}{$\begin{array}{l}\text { Толерант- Диагональ- } \\
\text { ность }\end{array}$} & \multicolumn{1}{l|}{$\begin{array}{l}\text { ные элемен- } \\
\text { ты обр. } \mathbf{X}^{\prime} \mathbf{X}\end{array}$} \\
\hline PR & 1,9425 & 0,4852 & 0,5148 & 0,0000 \\
\hline PC & 2,1384 & 0,5324 & 0,4676 & 0,0001 \\
\hline CL & 1,0844 & 0,0779 & 0,9221 & 0,0000 \\
\hline TM & 1,0907 & 0,0831 & 0,9169 & 3,0227 \\
\hline FL & 1,0738 & 0,0687 & 0,9313 & 0,5791 \\
\hline SS & 1,0036 & 0,0036 & 0,9964 & 18,5330 \\
\hline D1 & 1,5889 & 0,3706 & 0,6294 & 0,0073 \\
\hline D2 & 1,6779 & 0,4040 & 0,5960 & 0,0054 \\
\hline D3 & 1,5856 & 0,3693 & 0,6307 & 0,0057 \\
\hline
\end{tabular}

\begin{tabular}{|c|c|c|c|c|}
\hline № п/ІІІ & $\begin{array}{l}\text { Собствен- } \\
\text { ное } \\
\text { значение }\end{array}$ & $\begin{array}{l}\text { Возрас- } \\
\text { тающий \% }\end{array}$ & $\begin{array}{l}\text { Кумуля- } \\
\text { тивный \% }\end{array}$ & $\begin{array}{l}\text { Условные } \\
\text { числа }\end{array}$ \\
\hline 1 & 1,7996 & 20,0000 & 20,0000 & 1,0000 \\
\hline 2 & 1,4598 & 16,2200 & 36,2200 & 1,2300 \\
\hline 3 & 1,3780 & 15,3100 & 51,5300 & 1,3100 \\
\hline 4 & 1,0749 & 11,9400 & 63,4700 & 1,6700 \\
\hline 5 & 1,0070 & 11,1900 & 74,6600 & 1,7900 \\
\hline 6 & 0,8697 & 9,6600 & 84,3200 & 2,0700 \\
\hline 7 & 0,8279 & 9,2000 & 93,5200 & 2,1700 \\
\hline 8 & 0,3227 & 3,5900 & 97,1100 & 5,5800 \\
\hline 9 & 0,2605 & 2,8900 & 100,0000 & 6,9100 \\
\hline
\end{tabular}

Все условные числа меньше 100, следовательно, мультиколлинеарности нет.

ВЫВОД: В модели мультиколлинеарность и автокорреляция отсутствуют. 


\section{Список литературы}

1. Baysinger B., Kosnik R., Turk T. Effects of Board and Ownership Structure on Corporate R\&D Strategy The Academy of Management Journal, Vol. 34, № 1 (1991), pp. 205-214.

2. Craswell A., Taylor S., Saywell R. Ownership structure and Corporate Performance: Australian Evidence. Pacific-Basin Finance Journal, 5(3) (1997), pp.297-319.

3. Hansen G., Hill C. Are Institutional Investors Myopic? A Time-Series Study of Four Technology-Driven Industries. Strategic Management Journal, 12 (1) (1991), pp. 1-16.

4. Hayes R., Schaefer S. Implicit Contracts and the Explanatory Power of Top Executive Compensation for Future Performance. The RAND Journal of Economics, Vol. 31, № 2. (2000), pp. 273-293.

5. Graves S. Institutional ownership and corporate R\&D in the Computer Industry. The Academy of Management Journal, 31(2) (1988), pp. 417-428.

6. Firth M. The Remuneration of CEOs and Corporate Financial Performance in Norway. Managerial and Decision Economics, 17(3) (1996), pp. 291-301.

7. Kochhar R., Parthiban D. Institutional Investors and Firm Innovation: A Test of Competing Hypotheses. Strategic Management Journal 17 (1996), pp. 73-84.

8. Main B., Bruce A., Buck T. Total Board Remuneration and Company Performance. Economic Journal, 106(439) (1996), pp. 1627-1644

9. Moerland P. Corporate ownership and control structures: An international comparison. Review of industrial organisation, 10(4) (1996), pp. 443-164

10. Sudipta B., Hwang L., Mitsudome T., Weintrop J. Corporate governance, top executive compensation and firm performance in Japan., Pacific-Basin Finance Journal 15 (2007), pp. 56-79.

11. Tevlin S. CEO Incentive Contracts, Monitoring Costs, and Corporate Performance. New England Economic Review, 0 (0) (1996), 39-50.

12. Zhou X. CEO Pay, Firm Size, and Corporate Performance: Evidence from Canada. The Canadian Journal of Economics / Revue canadienne d'Economique, Vol. 33, № 1. (2000), pp. 213—251. 